\title{
Journal of Intensive Care Medicine
}

http://jic.sagepub.com

\section{Cyclic Appearance of Left Ventricular Outflow Tract Dynamic Obstruction During Mechanical Ventilation: Evidence for a Preload Dependent Phenomenon \\ Jean-Luc Canivet, Patrizio Lancellotti, Marc Radermecker and Pierre Damas \\ J Intensive Care Med 2008; 23; 281 originally published online May 28, 2008; \\ DOI: $10.1177 / 0885066608318662$}

The online version of this article can be found at:

http://jic.sagepub.com/cgi/content/abstract/23/4/281

\author{
Published by: \\ (SAGE \\ http://www.sagepublications.com
}

Additional services and information for Journal of Intensive Care Medicine can be found at:

Email Alerts: http://jic.sagepub.com/cgi/alerts

Subscriptions: http://jic.sagepub.com/subscriptions

Reprints: http://www.sagepub.com/journalsReprints.nav

Permissions: http://www.sagepub.com/journalsPermissions.nav

Citations http://jic.sagepub.com/cgi/content/refs/23/4/281 


\title{
Ventilation: Evidence for a Preload Dependent Phenomenon
}

\author{
Jean-Luc Canivet, MD, Patrizio Lancellotti, MD, PhD, \\ Marc Radermecker, MD, PhD, and Pierre Damas, MD, PhD
}

The cyclic appearance of dynamic left ventricular outflow tract obstruction during mechanical ventilation, according to the phasic changes in preload, is described in this article. Hemodialysis-induced fluid removal resulted in preload dependence as evidenced by the pulse pressure variation in a 56-year-old critically ill patient. The clinical picture was suggestive of myocardial failure. Transthoracic echocardiography disclosed dynamic left ventricular outflow tract obstruction associated with systolic anterior motion of the mitral valve. Progressive fluid restitution resulted in a parallel decrease in both the degree of dynamic obstruction and pulse pressure variation. During fluid loading, dynamic obstruction disappeared at first during the inspiratory phase of intermittent positive pressure ventilation corresponding to the phasic increase in left ventricular preload. Further fluid loading resulted in the disappearance of dynamic obstruction during both inspiratory and expiratory phase of intermittent positive pressure ventilation. This is the first reported case clearly relating left ventricular outflow tract dynamic obstruction to preload dependence during mechanical ventilation in a critically ill patient without predisposing anatomical factor.

Keywords: dynamic left ventricular outflow tract obstruction; mechanical ventilation; preload dependence
$\mathrm{D}$ ynamic forms of subvalvular left ventricular outflow tract obstruction (LVOTO) have been extensively described in various conditions. ${ }^{1}$ Routine use of echocardiography in our clinical practice has shown that dynamic LVOTO is less uncommon than previously thought in critically ill patients even in absence of any anatomical predisposing factor. This condition can mimick cardiogenic shock but requires completely opposed therapeutic

From the Departments of General Intensive Care (J-LC, PD), Cardiology (PL), and Cardiothoracic and Vascular Surgery (MR), University Hospital Centre, University of Liege, Domaine Universitaire du Sart-Tilman, Liege, Belgium.

Address correspondence to: Jean-Luc Canivet, MD, Department of General Intensive Care, University Hospital Centre, University of Liege, Domaine Universitaire du Sart-Tilman, B-4000 Liege, Belgium; e-mail: Jean-Luc.Canivet@chu.ulg.ac.be. interventions. ${ }^{2}$ Fluid removal and subsequent restitution during hemodialysis in a patient with septic shock provided us the opportunity to observe the variation in dynamic LVOTO, which was related to the ventilatory cycle. This observation highlights the predominantly preload dependent nature ${ }^{3}$ of dynamic LVOTO when it occurs in the absence of any anatomical predisposing factor.

\section{Case Report}

A 56-year-old woman was admitted in the intensive care unit (ICU) because of septic shock (Enterococcus faecalis bacteremia). On intermittent positive pressure ventilation (IPPV), (volume control mode with tidal volume of $10 \mathrm{~mL} / \mathrm{kg}$ and positive end-expiratory pressure of $8 \mathrm{~cm} \mathrm{H}_{2} \mathrm{O}, \mathrm{FiO}_{2}$ of 0.5 ), 
blood gases were as follows: $\mathrm{pH}, 7.37 ; \mathrm{PaCO}_{2}, 32 \mathrm{~mm}$ $\mathrm{Hg} ; \mathrm{PaO}_{2}, 93 \mathrm{~mm} \mathrm{Hg}$; and base deficit, 7. The patient was treated with continuous infusion of norepinephrine: blood pressure (BP), 110/60 mm Hg; heart rate (HR), 102 beats per minute (bpm; sinus rythm); central venous pressure, $13 \mathrm{~mm} \mathrm{Hg}$.

Hemodialysis was initiated because of acute renal failure and persisting oliguria despite a positive cumulative fluid balance of $10 \mathrm{~kg}$. After fluid removal of $1.5 \mathrm{~L}$, severe arterial hypotension occured (65/ $40 \mathrm{~mm} \mathrm{Hg}$ ). Heart rate was $110 \mathrm{bpm}$ (sinus rythm). The patient presented with clinical signs of pulmonary edema and arterial desaturation $\left(\mathrm{SpO}_{2} 85 \%\right)$. Clinical examination disclosed a new systolic murmur. Central venous pressure was $15 \mathrm{~mm} \mathrm{Hg}$, but invasive arterial monitoring displayed a hemodynamic profile suggestive of severe preload dependence: pulse pressure variation (PPV) was 35\%. ${ }^{3}$ Close observation of the arterial pressure curve revealed a biphasic appearance of the pulse pressure, the so-called bisferiens pulse. This prompted us to perform transthoracic echocardiography. Bidimensional examination disclosed systolic anterior motion (SAM) of the mitral valve. Continuous wave Doppler analysis of the subaortic flow revealed a typical dagger blade shape appearance with a end systolic acceleration of $6 \mathrm{~m} / \mathrm{s}$, suggesting a pressure gradient around $100 \mathrm{~mm} \mathrm{Hg}$ (simplified Bernoulli equation). Color Doppler examination disclosed severe mitral regurgitation associated with SAM. Left ventricular cavity was markedly reduced but parietal thickness was within normal range.

\section{Results}

At onset of LVOTO after $1.5 \mathrm{~L}$ of fluid removal, blood pressure was $60 / 41 \mathrm{~mm} \mathrm{Hg}$ and $\mathrm{HR}$ was 110 bpm. Pulse pressure variation (35\%) was suggestive of severe preload dependence, and a bisferiens arterial pulse was observed during both inspiratory and expiratory phase of IPPV (Figure 1A). There was a major endsystolic acceleration of the subaortic flow (maximal velocity $\sim 6 \mathrm{~m} / \mathrm{s}$ ) with a typical dagger blade shape (Figure 1B). This aspect associated with SAM (Figure 1C) persisted during the whole respiratory cycle.

After partial fluid restitution $(\sim 1 \mathrm{~L})$, blood pressure was 97/51 mm $\mathrm{Hg}$ and $\mathrm{HR}$ was $101 \mathrm{bpm}$. Pulse pressure variation decreased somewhat to $25 \%$ (Figure 2A). Bisferiens pulse was observed only during the expiratory phase. Endsystolic subaortic flow

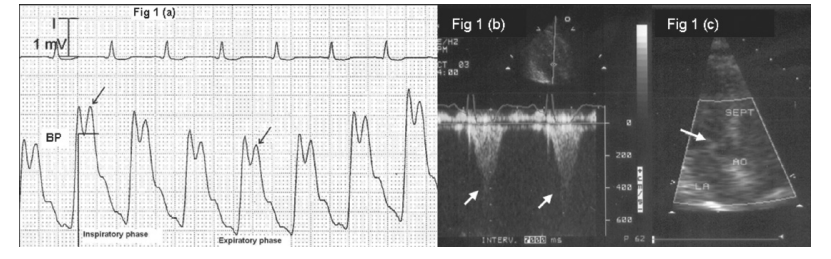

Figure 1. A, Blood pressure (BP): bisferiens arterial pulse (arrows), pulse pressure variation, 35\%. B, Continuous wave Doppler analysis of the subaortic flow: subaortic flow acceleration with dagger blade shape (arrows). C, systolic anterior motion (arrow); Left atrium (LA), aortic root (AO), interventricular septum (SEPT).

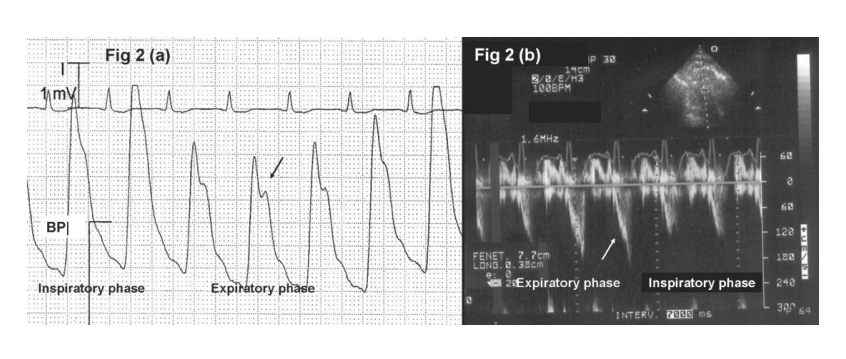

Figure 2. A, Blood pressure (BP): persistence of bisferiens arterial pulse (arrow), pulse pressure variation, 25\%. B, Continuous wave Doppler analysis of the subaortic flow: subaortic flow acceleration (arrow), during the expiratory phase.

acceleration progressively decreased to 2 to $3 \mathrm{~m} / \mathrm{s}$ and eventually persisted only during the expiratory phase (Figure 2B).

After total fluid restitution ( $2 \mathrm{~L})$, blood pressure was 122/55 mm $\mathrm{Hg}$ and PPV was markedly reduced to $12 \%$, which were, therefore, below the threshold value for preload dependence. ${ }^{3}$ Heart rate was $90 \mathrm{bpm}$. No bisferiens pulse (Figure 3A), no SAM, nor significant endsystolic flow acceleration (Figure 3B) was observed during the whole respiratory cycle. At this time, systolic murmur totally disappeared, and pulmonary edema progressively resolved. The main results are graphically summarized in Figure 4.

\section{Discussion}

Subaortic dynamic obstruction most often involves the association of an anatomical predisposition and hemodynamic conditions favoring the systolic anterior excursion of the mitral leaflets. Anatomical predisposing factors may be specific for some peculiar 


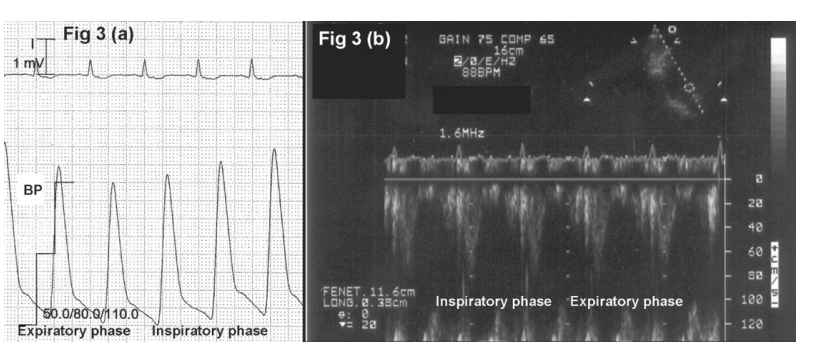

Figure 3. A, Blood pressure (BP): disappearance of bisferiens arterial pulse, pulse pressure variation, $10 \%$. B, Disappearance of significant subaortic flow acceleration throughout the whole respiratory cycle.

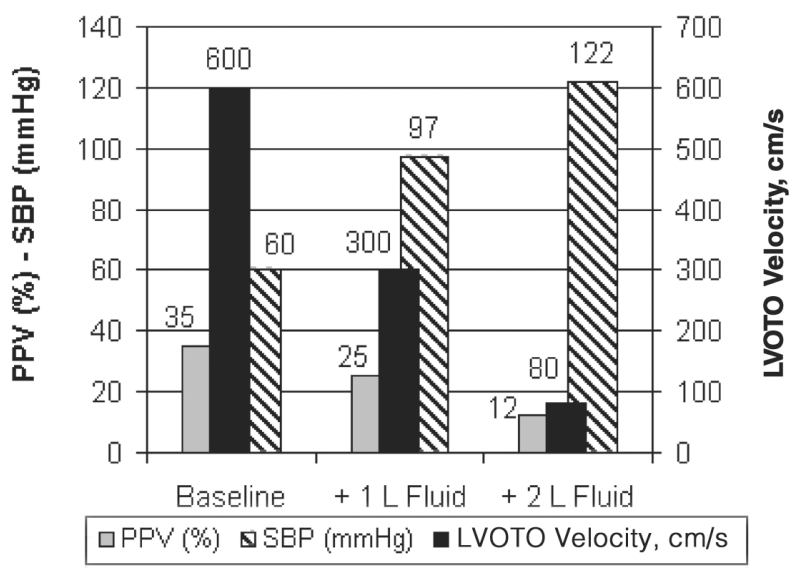

Figure 4. Changes in PPV, SBP, and LVOTO velocity, according to fluid restitution. PPV indicates pulse pressure variation; SBP, systolic blood pressure; LVOTO, left ventricular outflow tract obstruction.

diseases such as hypertrophic obstructive cardiomyopathy, postoperative status after aortic valve replacement for stenosis, and mitral valve repair. ${ }^{1}$ In the general ICU patient, the most frequently encountered predisposing factors include symmetric concentric LV hypertrophy, septal bulging, and posterior calcification of the mitral valve, which are most often seen in elderly patients with a longstanding history of arterial hypertension. ${ }^{4}$

However, dynamic LVOTO may occur in absence of any evident anatomical predisposing factor as demonstrated by autopsy study. ${ }^{5}$ Intracardiac hemodynamic abnormalities leading to SAM involve excessive left ventricular outflow acceleration and reduction in lateral pressure resulting in Venturi effect attracting the anterior leaflet of the mitral valve. ${ }^{1}$ Severe hypovolemia with $\mathrm{LV}$ cavity systolic obliteration, severe vasoplegia, and inappropriate inotropic stimulation are the most common conditions associated with left ventricular outflow acceleration. ${ }^{5}$ The cyclic appearance of SAM during the expiratory phase of intermittent positive pressure ventilation highlights the preload dependence of this phenomenon. Fluid removal by hemodialysis induced a severe preload dependence as disclosed by the major increase in PPV. ${ }^{3}$ Intracardiac flow acceleration and SAM occurred in close relationship with the PPV increase. Fluid restitution induced a progressive decrease in intracardiac velocity and the disappearance of SAM in close temporal relationship with the decrease in PPV (Figure 4). During fluid loading, these changes occurred first during the inspiratory phase of IPPV corresponding to the phasic increase in $L V$ preload $^{6}$ and with progressive filling extended to both inspiratory and expiratory phases.

The main hemodynamic consequences of SAMinduced LVOTO are as follows: the addition of a resistive factor to the left ventricular outflow responsible for a dynamic form of obstructive shock and a moderate to severe mitral regurgitation due to the anterior displacement of the anterior mitral leaflet resulting in a coaptation defect.

These hemodynamic disturbances can result in a clinical picture of cardiogenic shock, which typically remains unresponsive to conventional therapy (inotropes and diuretics). ${ }^{2,5}$ Both subaortic narrowing and mitral regurgitation contribute to the occurrence of a new systolic murmur. ${ }^{7}$ The obstructive phenomenon can explain the appearance of bisferiens arterial pulse on the arterial monitoring. ${ }^{8}$ Bisferiens pulse has a waveform characterized by 2 positive systolic peaks: the first one rises rapidly early in the systole, and the second one, somewhat smaller and slower, occurs after a small decline in pressure in the late systole. Bisferiens pulse is explained by the midsystolic drop in $\mathrm{LV}$ ejection due to SAM and late systolic reincrease due to mitralseptal separation. ${ }^{8}$ However, bisferiens pulse is not specific for SAM-related LVOTO as it may be encountered in various conditions associated with the rapid ejection of the stroke volume (aortic regurgitation, fever, and vasoplegia). ${ }^{9}$

In conclusion, dynamic LVOTO may arise in critically ill patients without any predisposing anatomical factor. The data presented here illustrate the exceedingly high preload dependence of this 
phenomenon. The association of cardiogenic shock, new systolic murmur, bisferiens pulse, and increased pulse pressure variation could be suggestive of the diagnosis. A paradoxical worsening response to conventional treatment (inotropes and diuretics) should prompt to perform echocardiography, which definitely provides the diagnosis.

\section{References}

1. Radermecker M, Canivet JL, Lancellotti P, Limet R. The usual causes of left ventricular outflow tract obstruction below the aortic valve in normal ventriculoarterial connection: review of the physiopathology and surgical implications. Acta Chir Belg. 2005;105:475-481.

2. Madu EC, Brown R, Geraci SA. Dynamic left ventricular outflow tract obstruction in critically ill patients: role of transoesophageal echocardiography in therapeutic decision making. Cardiology. 1997;88:292-295.

3. Michard F, Boussat S, Chemla D, et al. Relation between respiratory changes in arterial pulse pressure and fluid responsiveness in septic patients with acute circulatory failure. Am J Respir Crit Care Med. 2000;162:134-138.

4. Topol EJ, Traill TA, Fortuin NJ. Hypertensive hypertrophic cardiomyopathy in the elderly. $N$ Engl J Med. 1985;312:277-283.

5. Bulkley BH, Fortuin NJ. Systolic anterior motion of the mitral valve without asymmetric septal hypertrophy. Chest. 1976;69:694-696.

6. Michard F. Changes in arterial pressure during mechanical ventilation. Anesthesiology. 2005;103:419-428.

7. Haley JH, Sinak LJ, Ommen SR, Oh JK. Dynamic left ventricular outflow tract obstruction in acute coronary syndromes: an important cause of new systolic murmur and cardiogenic shock. Mayo Clin Proc. 2000;74:901-906.

8. Conklin HM, Huang X, Davies CH, Sahn DJ, Shively BK. Biphasic left ventricular outflow and its mechanism in hypertrophic obstructive cardiomyopathy. J Am Soc Echocardiogr. 2004;17:375-383.

9. O'Rourke RA, Shaver JA, Salerni R, Silverman ME, Schlant RC. The history, physical examination and cardiac auscultation. In: McGraw-Hill, ed. Hurst's the Heart. 11 th ed. New York, NY: McGraw-Hill; 1998:229-342. 